\section{Tumores hipofisários secretores de TSH: relato de dois casos e revisão da literatura}

\author{
TSH-secreting pituitary tumors: two case reports and literature review
}

Felipe Henning Gaia Duarte', Raquel Soares Jallad', Luiz Roberto Salgado', Marcello Delano Bronstein'

\section{RESUMO}

Introdução: Tumores hipofisários secretores de hormônio estimulante da tireoide (TSH), tireotropinomas, são raros e correspondem a menos de $2 \%$ de todos os adenomas da hipófise. Manifestam-se clinicamente com sintomas e sinais de tireotoxicose, eventualmente associados a sintomas compressivos, sobretudo visuais, devido ao efeito de massa do tumor. Esses tumores se caracterizam pela presença de níveis séricos elevados de hormônios tireoidianos e níveis séricos elevados, ou inapropriadamente normais, deTSH. Frequentemente, ao diagnóstico, há relato de tratamento prévio cirúrgico, medicamentoso e/ou ablativo, por hipótese de hipertireoidismo primário por doença de Graves. Objetivo: Relatar dois casos de tireotropinomas acompanhados na Unidade de Neuroendocrinologia do Hospital das Clínicas da Faculdade de Medicina da Universidade de São Paulo (HC-FMUSP) e revisar a literatura visando ao manejo desta afecção. Conclusão: Na presença de hormônios tireoidianos elevados e níveis deTSH inapropriadamente normais ou elevados, a possibilidade de adenoma hipofisário produtor deTSH deve ser considerada com vistas à realização da terapia adequada. Arq Bras Endocrinol Metab. 2009;53(9):1157-66

Descritores

Tumores secretores de TSH; tireotropinomas; TSH-omas; adenomas hipofisários secretores de TSH

\section{ABSTRACT}

Introduction: TSH-secreting pituitary adenomas are rare pituitary functioning tumors accounting for less than $2 \%$ of the pituitary adenomas. The clinical feature consists of thyrotoxicosis occasionally associated to tumoral symptoms due to mass effect. The biochemical feature consists of elevated thyroid hormones levels and normal or high TSH concentrations. This disease is often wrongly diagnosed as Grave's disease, and the ablative therapy is frequently conducted prior to the diagnosis. Objective: To report two cases followed in the Neuroendocrine Unit of Hospital das Clínicas, Faculdade de Medicina, Universidade de São Paulo and to review the literature aiming at the management of this affection. Conclusion: In the presence of elevated thyroid hormone levels associated with inappropriate normal or increasedTSH levels, the possibility of aTSH-secreting pituitary adenoma should be considered for the proper medical treatment. Arq Bras Endocrinol Metab. 2009;53(9):1157-66

Keywords

TSH-secreting pituitary tumors; thyrotropinomas; TSH-omas; TSH-secreting pituitary adenomas

\author{
1 Unidade de Neuroendocrinologia, \\ disciplina de Endocrinologia \\ e Metabologia, Hospital das \\ Clínicas, Faculdade de Medicina, \\ Universidade de São Paulo \\ (HC-FMUSP), São Paulo, SP, Brasil
}

Correspondência para:

Felipe Henning Gaia Duarte

Av. Doutor Enéas de Carvalho Aguiar, 255

PAMB $8^{\circ}$ andar, Andar, bloco 3 05403-000 - São Paulo, SP, Brasil felipe_gaia1@hotmail.com

Recebido em 16/Nov/2008 Aceito em 9/Set/2009

\section{INTRODUÇÃO}

— ste artigo visa relatar o caso de dois pacientes porUtadores de tireotoxicose secundária à presença de tumor hipofisário produtor de TSH e revisar a literatura quanto ao diagnóstico clínico, laboratorial e radiológico, e ao tratamento dessa doença. O principal diagnóstico diferencial é com a síndrome de resistência aos hormônios tireoidianos (SRHT).

\section{DESCRIÇÃO DOS CASOS}

\section{Caso 1}

Paciente do sexo feminino, 46 anos, procurou o serviço do Hospital das Clínicas da Faculdade de Medicina da Universidade de São Paulo após diagnóstico prévio de tireotoxicose e indicação de terapêutica ablativa com 131I. Referia perda de peso $(6 \mathrm{~kg})$, tremores finos de 
extremidades, taquicardia e sudorese havia quatro meses. Negava cefaleia, galactorreia, alterações menstruais e distúrbios visuais. Estava em tratamento apenas com propranolol (40 mg 2x/dia). Ao exame físico, ausência de sinais clínicos de tireotoxicose, tireoide discretamente aumentada, indolor e sem nódulos. A avaliação laboratorial revelou concentrações elevadas de T4 livre e de subunidade alfa, TSH no limite superior da normalidade, restante da função hipofisária normal e pesquisa de autoimunidade tireoidiana negativa (Tabela 1 , caso 1 ). A ressonância magnética (RM) de hipófise demonstrou macroadenoma hipofisário (Figura 1). A ultrassonografia (US) da tireoide revelou glândula de volume discretamente aumentado com textura heterogênea. No teste agudo com injeção de octreotida na formulação subcutânea (OCT-sc), $100 \mu \mathrm{g}$, houve redução parcial $(46 \%)$ dos níveis do TSH $(4,2 \mathrm{mU} / \mathrm{mL}$ versus $2,3 \mathrm{mU} / \mathrm{mL}$, basal versus $4 \mathrm{~h}$ após Oct).
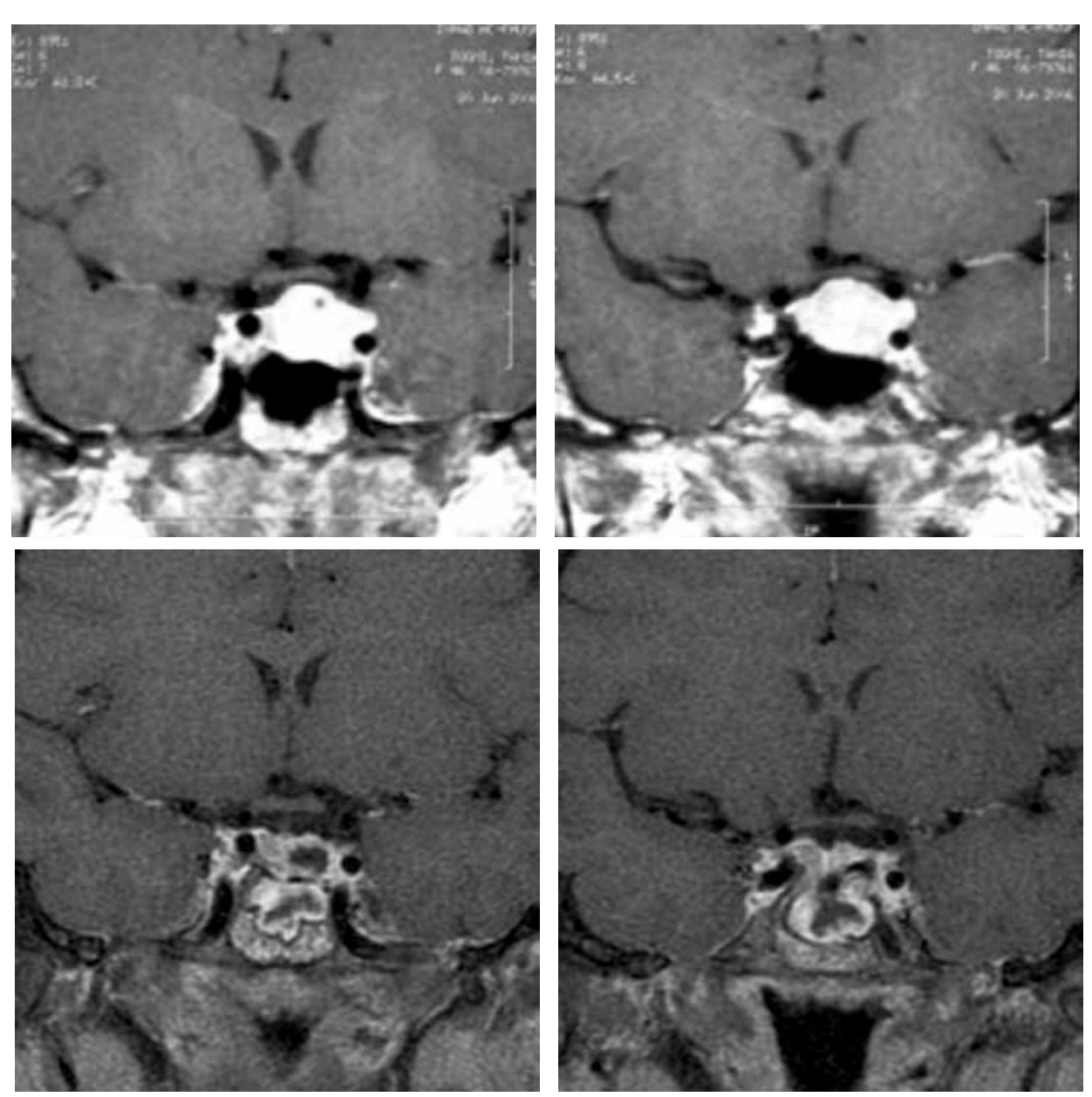

Figura 1. Ressonância de magnética (RM) de hipófise: imagens superiores; cortes coronais em $T 1$ com contraste. Lesão de 1,8 cm, captante de contraste, ocupando a região selar com extensão suprasselar em direção ao quiasma óptico e com uma discreta insinuação para a região parasselar esquerda (caso 1). Imagens inferiores; RM três meses após a cirurgia por via transesfenoidal, mostrando remoção parcial do tumor.

\begin{tabular}{|c|c|c|}
\hline & Caso 1 & Caso 2 \\
\hline TSH (0,4 - 4,5 U/mL) & 4,1 & 7,7 \\
\hline T4L (0,7 - 1,5 ng/dL) & 2,5 & 2,94 \\
\hline T4T (4,5 - $12 \mu \mathrm{U} / \mathrm{mL})$ & 16,1 & \\
\hline ТЗТ (70 - 200 ng/dL) & 169 & 204 \\
\hline Anti-TG (UI/mL) & negativo & negativo \\
\hline Anti-TPO (UI/mL) & negativo & negativo \\
\hline TRAB (\%) & negativo & negativo \\
\hline Subunidade $\alpha(<600 \mu \mathrm{g} / \mathrm{L})$ & 780 & 5.170 \\
\hline LH (UI/L) & 5,2 & 1 \\
\hline $\mathrm{FSH}(\mathrm{UI} / \mathrm{L})$ & 7,2 & 1 \\
\hline GH (até 4,4 ng/mL) & 0,2 & 1,8 \\
\hline IGF 1 (94 - 252 ng/mL) & 94 & 196 \\
\hline Prolactina (2 - 15 ng/mL) & 11,2 & 23 \\
\hline ACTH (até 80 pg/mL) & 32 & \\
\hline \multicolumn{3}{|l|}{ DHEAS ( $\mu \mathrm{g} / \mathrm{dL})$} \\
\hline F sérico $(5,4-25 \mu \mathrm{U} / \mathrm{dL})$ & 13,8 & 38 \\
\hline
\end{tabular}


Após o diagnóstico, a paciente foi submetida ao tratamento com OCT-sc (100 $\mu \mathrm{g} 8 / 8$ horas e, posteriormente, $200 \mu \mathrm{g} 8 / 8$ horas), visando ao controle do hipertireoidismo. Houve redução, mas não normalização dos níveis hormonais. O Oct foi suspenso e introduziuse o metimazol com normalização, dos níveis de T4 livre e elevação do TSH (Tabela 2, caso 1). A paciente foi submetida à cirurgia transesfenoidal com remoção parcial do tumor e normalização hormonal.

\section{Caso 2}

Paciente, sexo feminino, 23 anos, com queixas de taquicardia e sudorese há cerca de dois anos. Negava perda de peso e outros sintomas de tireotoxicose. Estava em uso de anticoncepcional oral. Ao exame físico, frequência cardíaca 100 bpm, pressão arterial 110/70 mmHg, ausência de sinais oculares, tireoide palpável e com superfície regular, extremidades quentes e úmidas. À avaliação laboratorial, aumento dos níveis de T4 livre, de TSH e da subunidade alfa (Tabela 1, caso 2). À RM de hipófise, presença de macroadenoma (Figura 2). Ao exame neurooftalmológico, presença de quadrantopsia superior temporal bilateral.

Com o intuito de normalizar a função tireoidiana para cirurgia subsequente, foi realizado o tratamento com OCT-sc (100 mg 8/8 horas), com redução mar-

\begin{tabular}{|c|c|c|c|c|}
\hline Caso 1 & Basal & $\begin{array}{c}\text { Propranolol } 80 \text { mg/dia + } \\
\text { Octreotide SC } 200 \text { 8/8h }\end{array}$ & $\begin{array}{l}\text { Propranolol } 80 \mathrm{mg} / \mathrm{dia}+ \\
\text { Tapazol } 60 \mathrm{mg}\end{array}$ & Pós-cirurgia, sem medicação \\
\hline $\mathrm{TSH}(\mu \mathrm{U} / \mathrm{mL})$ & 4,1 & 2,2 & 11,9 & 1,4 \\
\hline T4L (ng/dL ) & 2,5 & 2,0 & 1,5 & 1,0 \\
\hline Caso 2 & Basal & $\begin{array}{l}10 \text { dias Octreotide SC } \\
100 \mathrm{mcg} 8 / 8 \mathrm{~h}\end{array}$ & $\begin{array}{l}7 \text { dias após } 0 \text { ctreotide } \\
\text { LAR } 20 \mathrm{mcg}\end{array}$ & $\begin{array}{l}26 \text { dias após } 2^{\mathrm{a}} \text { aplicação 0ctreotide } \\
\text { LAR } 20 \mathrm{mcg}\end{array}$ \\
\hline $\mathrm{TSH}(\mu \mathrm{U} / \mathrm{mL})$ & 7,7 & 3,3 & 3,6 & 1,1 \\
\hline T4L (ng/dL ) & 2,94 & 1,95 & 1,6 & 1,1 \\
\hline Subunidade alfa $(\mu / \mathrm{L})$ & 5.170 & & 1.170 & \\
\hline
\end{tabular}
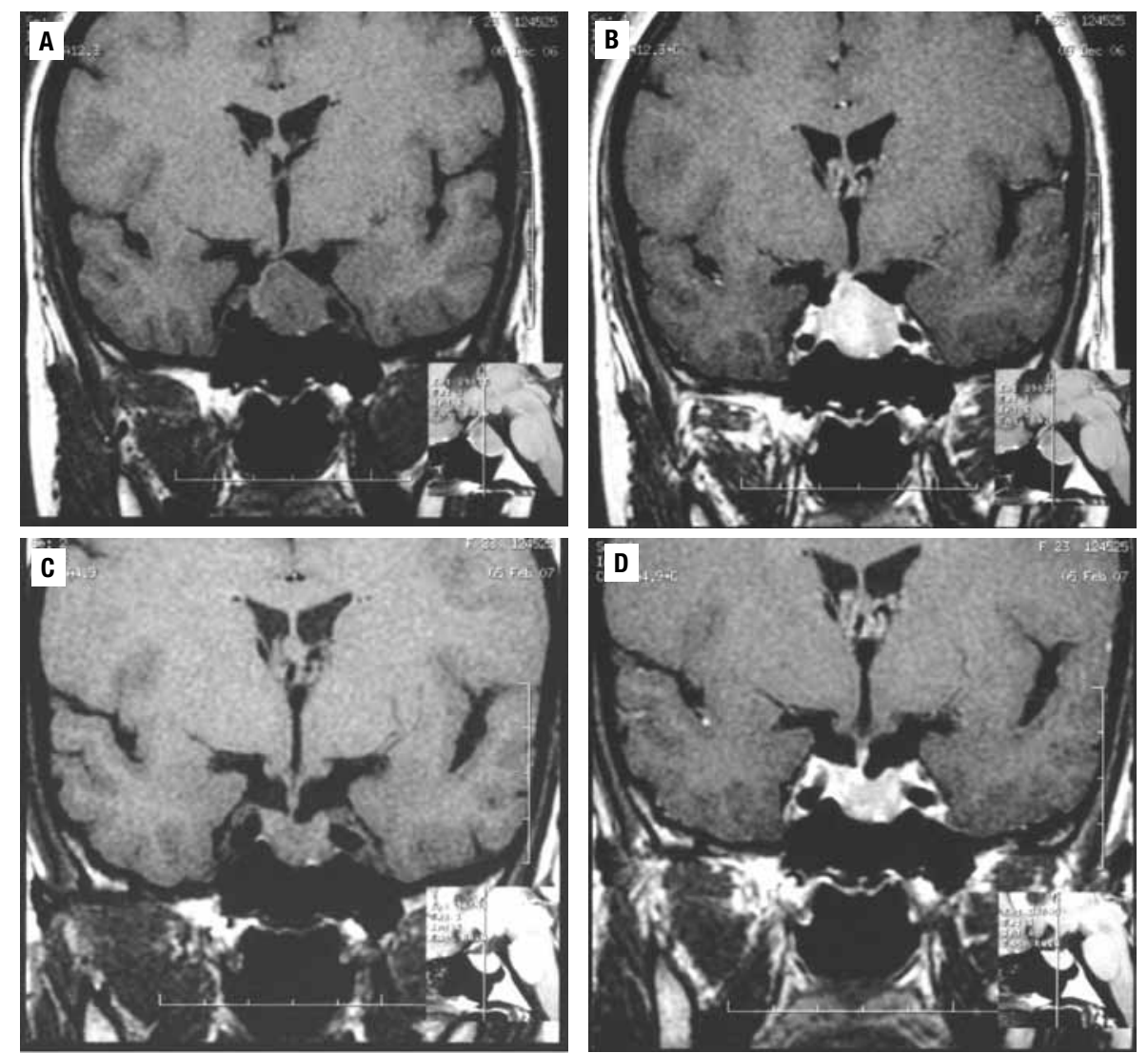

Figura 2. Ressonância de magnética (RM) de hipófise. Cortes coronais em T1 pré (A) e pós (B) injeção de contraste: tumor homogêneo, predominantemente intrasselar com extensão em direção ao quiasma ótico abaulando o contorno suprasselar. Imagens inferiores evidenciando diminuição tumoral após dois meses de tratamento com análogo de somatostatina (C e D). 
cante dos valores de TSH e T4 livre. Com a substituição pelo OCT de liberação prolongada (Long-Acting Repeatable, OCT-LAR), houve normalização hormonal e redução da subunidade alfa (Tabela 2, caso 2). Após a segunda aplicação do medicamento, foram observadas redução importante do volume tumoral e regressão do quadro visual (Figura 2). Em função desses resultados, optou-se pela manutenção do tratamento clínico.

\section{REVISÃO DA LITERATURA}

Os tumores hipofisários secretores de TSH, também chamados de TSH-omas ou tireotropinomas, tiveram sua primeira descrição na literatura feita por Jailer e Holub (1), que relataram um paciente com tireotoxicose e concentração elevada de TSH, determinada por bioensaio. O primeiro caso de TSH-oma com o TSH dosado por RIA foi relatado na década de 1970 (2) e, desde então, com a introdução de metodologias ultrassensíveis, vem ocorrendo um aumento importante na detecção desses tumores. Ainda assim, é uma doença rara, como documenta revisão realizada em 1996 por Beck-Peccoz (3), que identificou 280 pacientes descritos na literatura.

\section{Etiologia}

$\mathrm{Na}$ quase totalidade dos casos, a produção excessiva de TSH está associada à presença de um adenoma hipofisário benigno. Há relato de um caso de adenoma localizado na nasofaringe (4). Também foram descritos dois casos de carcinomas secretores de TSH $(5,6)$, sendo que um deles originou-se de um adenoma clinicamente não funcionante que evoluiu com metástases secretoras de TSH e PRL (6).

\section{Fisiopatologia}

$\mathrm{Na}$ maioria dos casos, há hipersecreção apenas de TSH $(72,1 \%)$. Várias isoformas de TSH (7) com diferentes composições de resíduos de oligossacarídeos (8) e com atividade biológica variável podem ser identificadas. A variabilidade na atividade biológica dessas isoformas pode justificar os casos com TSH inapropriadamente normal e níveis elevados de hormônios tireoidianos e a heterogeneidade clínica entre esses tumores.

Além da hipersecreção de TSH, pode haver cossecreção de um segundo hormônio como GH $(15,7 \%)$, PRL (10,7\%), FSH e LH (1,4\%) e, mais raramente, de mais de dois hormônios (3). Não há casos relatados de cossecreção de ACTH.
A capacidade de supressão da secreção de TSH tumoral pelo T3, avaliada em cultura de células tumorais, é variável de acordo com o estudo. Alguns demonstraram ausência de efeito do T3 na secreção do TSH $(7,9)$, enquanto outros evidenciaram redução ou mesmo bloqueio na secreção do TSH estimulada pelo TRH (10-11).

\section{Patogênese molecular}

Os mecanismos moleculares que levam ao desenvolvimento dos tireotropinomas não são bem estabelecidos. Como os demais adenomas hipofisários, eles resultam da expansão monoclonal de uma célula adeno-hipofisária transformada (12). No entanto, os estudos in vitro não identificam mutações especificamente ligadas à sua tumorigênese $(3,13)$. Entre os diversos candidatos, apenas o Pit-1 mostrou-se hiperexpresso nos tumores investigados (14). Entre os oncogenes, as mutações no gene Gsp, localizado no cromossomo $20 \mathrm{q} 13$, também podem ser eventualmente encontradas (15). Apesar de alguns casos terem sido relatados em pacientes portadores de NEM 1, nenhuma mutação no gene da proteína menin foi encontrada nos estudos genéticos, tanto nos casos de NEM 1 como em tumores esporádicos (16-20). Analisando-se as amostras de cinco tireotropinomas, Ando e cols. (21) demonstraram, em um dos casos, a presença de uma mutação no receptor beta do hormônio tireoidiano, similar à encontrada na SRHT.

\section{Patologia}

Em relação aos aspectos histológicos e ultraestruturais, os tireotropinomas possuem consistência densa e fibrosa, característica associada à expressão aumentada do fator de crescimento dos fibroblastos (22). Suas células apresentam citoplasma misto, basófilo-acidófilo, com núcleos ovais uniformes e padrão cromófobo quando corado pela hematoxilina-eosina. A análise imunoistoquímica revela que quase todos os adenomas pesquisados são positivos para TSH- $\beta$ e subunidade alfa. Além desses dois marcadores, $80 \%$ dos casos foram positivos para GH e/ou PRL. Todos os adenomas expressaram a proteína Pit-1 (23). A microscopia eletrônica pode revelar células de tamanho médio ou mesmo grandes células angulares, núcleo uniforme, retículo endoplasmático rugoso dilatado e proeminente, área de Golgi extensa e número variável de grânulos de pequenas proporções (100 a $300 \mathrm{~nm}$ ) aglomerados. Alguns tumores exibem aspecto menos diferenciado, com núcleo irregular, cito- 
plasma escasso contendo retículo endoplasmático rugoso pouco desenvolvido, aparelho de Golgi inconspícuo e grânulos de secreção esparsos e pequenos, lembrando o adenoma de células nulas (24).

A presença de diversos subtipos do receptor de somatostatina (SSTR), pesquisada pela análise do mRNA, foi demonstrada nesses tumores, excetuando-se os SSTR4 e SSTR2b (25). Comparando à hipófise normal, a expressão foi variável entre os casos. O SSTR2a foi o mais expresso em comparação com os demais receptores. O SSTR 5 encontrava-se expresso em menor quantidade. Yoshiraha e cols. (26), em estudo semelhante, demonstraram a presença do mRNA para o SSTR2 em todos os casos da sua amostra e para o SSTR4 em apenas alguns casos.

Os receptores de dopamina também foram evidenciados nos tireotropinomas (27-28), sendo a sua presença e expressão variáveis nas amostras estudadas.

Estudos in vitro e in vivo para a identificação de receptores do TRH demonstraram resultados discordantes quanto à sua funcionalidade. In vivo, a estimulação por TRH leva a uma resposta usualmente ausente, enquanto, em estudos in vitro, foram observadas tanto ausência como presença de resposta (3). Alteração no sítio de ligação do receptor do TRH parece estar envolvida nos casos de ausência de resposta (10).

\section{Aspectos epidemiológicos e clínicos}

Os tireotropinomas compreendem 2,8\% dos adenomas hipofisários (29). Em trabalho de revisão de 280 casos de tireotropinomas, Beck-Peccoz e cols (3). observaram que estes tumores apresentam frequência similar em ambos os sexos e acometeram indivíduos entre 11 e 84 anos. Os pacientes apresentavam história de disfunção tireoidiana de longa duração com evolução progressiva e quadros variáveis desde franca tireotoxicose até ausência de quadro clínico, a despeito de concentrações elevadas de hormônios tireoidianos. Os tumores foram frequentemente confundidos com afecções primárias da tireoide e, em função disso, cerca de $1 / 3$ dos pacientes avaliados já haviam recebido terapia ablativa tireoidiana prévia. Essa situação também foi evidenciada em publicações posteriores, nas quais cerca de $45 \%$ dos pacientes com tireotropinoma atendidos no National Institute of Health (30) e $30 \%$ dos pacientes de um conjunto de centros belgas e franceses (19) receberam o diagnóstico prévio de tireotoxicose primária.

O bócio foi um achado frequente, presente em 94\% dos pacientes (3). Sintomas decorrentes da compressão de estruturas adjacentes por expansão extrasselar também foram observados. Alterações visuais foram constatadas em quase metade (42\%) e cefaleia em 1/6 (17\%) dos pacientes. Esses dados sugerem a presença de tumores grandes e invasivos e que, talvez, o diagnóstico tenha sido feito tardiamente em sua grande parte (3). A exoftalmia foi constatada em $6 \%$ dos casos, quer seja por associação com doença de Graves ou, quando unilateral, por invasão da órbita pelo tumor. Desordens do eixo gonadotrófico e galactorreia também foram observadas especialmente naqueles que cossecretavam prolactina. A presença de caracteres clínicos típicos de acromegalia também foi observada quando cossecretavam GH. Nesse subgrupo, os sintomas de tireotoxicose eram menos evidentes que os de acromegalia.

\section{Diagnóstico}

A base laboratorial para o diagnóstico consiste na detecção de concentrações elevadas dos hormônios tireoidianos diante de concentrações de TSH inapropriadamente normais ou elevadas. A presença de anticorpos antitireoidianos foi detectada em pequeno número de pacientes, sendo o TRAb encontrado em $4 \%$ e o antiTPO em $8 \%$ dos casos (3). Em $66 \%$ dos tireotropinomas, independentemente do tratamento tireoidiano prévio, observa-se a cossecreção elevada da subunidade alfa. A elevação do seu nível sérico e da sua relação molar com o TSH é altamente sugestiva de tireotropinoma. Nestes casos, também se observa uma redução da resposta do TSH ao TRH. Em presença da suspeita clínica e laboratorial de tireotropinoma, é imposta a realização de imagem da sela turca, RM preferencialmente, ou tomografia computadorizada. Como cerca de $80 \%$ desses tumores são macroadenomas, geralmente invasivos, a avaliação neurooftalmológica deve ser solicitada para afastar comprometimento visual e/ou neurológico (indicações de tratamento primário cirúrgico).

\section{Diagnóstico diferencial}

Diante do quadro clínico-laboratorial e de imagem acima referido, o diagnóstico de tireotoxicose de causa central por adenoma hipofisário está praticamente definido. Situações que interferem nas dosagens hormonais e na presença de um incidentaloma hipofisário em paciente com SRHT são raras, mas determinam a necessidade de um diagnóstico diferencial.

O principal diagnóstico diferencial a ser considerado é com a SRHT. Em alguns casos, especialmente nos 
pacientes que sofreram ablação tireoidiana prévia, isso pode não ser possível com as ferramentas de investigação habituais, tornando necessária a realização do estudo genético do subtipo beta do receptor do hormônio tireoidiano para a completa elucidação diagnóstica. Nos pacientes com tireoide intacta, Beck-Peccoz e Persani (31) destacam uma série de dados que podem ser úteis na diferenciação entre as duas afecções (Tabela 3 ). Entre esses dados, podem-se citar os seguintes:

\begin{tabular}{|c|c|c|}
\hline & TSH-oma & SRHT \\
\hline História Familiar & Negativa & Positiva \\
\hline SHBG & Elevada & Normal \\
\hline Subunidade $\alpha$ & Elevada & Normal \\
\hline Subunidade $\alpha / \mathrm{TSH}$ & Elevada & Normal \\
\hline Supressão TSH após T3 & Negativa* & Positiva \\
\hline Resposta TSH ao TRH & Negativa & Positiva \\
\hline Resposta TSH ao análogo de somatostatina & Positiva & Negativa \\
\hline Presença de tumor hipofisário & Positiva & Negativa \\
\hline
\end{tabular}

* Resposta pode ser parcial ou totalmente positiva.

1. História familiar de alterações dos hormônios (T4 livre e TSH). O relato de casos familiares é mais sugestivo de SRHT devido à ausência de relatos de tireotropinomas familiares.

2. TSH elevado. Concentrações elevadas de TSH sugerem a presença de tireotropinomas, embora possa ocorrer na SRHT, situação na qual o TSH é mais frequentemente normal $(30,31)$. Na revisão realizada por Beck-Peccoz e cols. (3), foi observado o comportamento do TSH em 236 tireotropinomas. Nos pacientes com tireoide intacta, que correspondiam a $2 / 3$ dos casos, o TSH estava elevado em $66 \%$ dos pacientes e os demais tinham esse hormônio dentro da normalidade. Nos pacientes submetidos à ablação tireoidiana prévia, o percentual de TSH elevado foi de $89 \%$. Os valores do TSH neste segundo grupo também foram significativamente maiores $(60$ versus $10 \mathrm{mUI} / \mathrm{L})$. Esses dois dados sugerem que a queda nas concentrações dos hormônios tireoidianos, provocada pela ablação tireoidiana, induz um aumento na atividade celular dos tireotrofos, que parecem manter certa sensibilidade aos efeitos supressivos do T3.

3. SHBG elevada. Sugere a existência de tireotoxicose e, portanto, a presença de tireotropinoma. A SHBG é uma proteína que se eleva nos pacientes com tireoto- xicose de qualquer natureza e pode ser usada como parâmetro da ação periférica dos hormônios tireoidianos. Os casos documentados de tireotropinomas com SHBG baixa eram de pacientes com acromegalia associada. Os casos de SRHT com SHBG alta eram de mulheres em reposição estrogênica e de homens com hipogonadismo grave. Outros marcadores de hipertireoidismo celular que também podem ser utilizados são: o CTX (telopeptídeo carboxiterminal do colágeno) e a ferritina. Na tireotoxicose, suas concentrações se elevam, mas se mantêm dentro da normalidade em pacientes com função tireoidiana normal ou na SRHT $(32,33)$.

4. Subunidade alfa elevada. Sugere a presença de tireotropinoma. Os microadenomas apresentaram uma maior propensão a terem valores normais (3). As concentrações da subunidade alfa se elevam naturalmente após a menopausa, seguindo as elevações das gonadotrofinas, o que deve ser considerado na análise das concentrações em mulheres no período do climatério $(3,34)$.

5. Relação subunidade alfa/TSH elevada. Sugere a presença de tireotropinoma. $\mathrm{O}$ cálculo dessa relação pode ser realizado por meio da seguinte equação: subunidade alfa $(\mu \mathrm{g} / \mathrm{L}) / \mathrm{TSH}(\mu \mathrm{UI} / \mathrm{L})$ x 10. Classicamente, uma relação superior a 1 é considerada sugestiva de tireotropinoma $(35,36)$. Estudo que subdividiu os pacientes em grupos de acordo com as concentrações de gonadotrofinas e de TSH propôs valores corrigidos visando a uma maior acurácia diagnóstica. Assim, o valor normal da relação seria menor que 5,7 em pacientes com gonadotrofinas e TSH normais, menor que 29,1 pacientes com gonadotrofinas elevadas e TSH normal e menor que $0,7 \mathrm{em}$ pacientes com gonadotrofinas normais e TSH elevado. Em 135 casos estudados (3), independentemente do tamanho tireoidiano prévio, verificou-se que $80 \%$ dos casos possuíam uma relação molar alterada.

6. Supressão completa do TSH pelo T3. Apesar de não ter valor preditivo positivo de $100 \%$, uma supressão importante, maior que $90 \%$, favorece a presença de SRHT. Este teste é baseado na maior sensibilidade da hipófise na SRHT e na insensibilidade relativa dos tireotropinomas aos efeitos supressivos de doses elevadas de T3. $\mathrm{O}$ teste de supressão proposto por Werner consiste na administração de T3 100 mcg à tarde por dez dias com a dosagem do TSH antes e após. Considera-se resposta normal uma redução de, no mínimo, 90\% em relação ao valor basal. Uma resposta anormal foi observada em todos os casos de tireotropinoma $(3,31)$, mas pode haver redução de cerca de $17 \%$ do TSH nesses tumores. Outra versão desse teste, proposta por Saad e cols. (37), 
consistiu na coleta de sangue para a determinação do TSH antes e após a administração de T3 $100 \mathrm{mcg}$ de $8 / 8$ horas por dois dias, utilizando-se o mesmo critério de resposta citado anteriormente. Esse teste foi utilizado na casuística do NIH (30) visando tanto a confirmar o diagnóstico quanto servir como critério de cura no pósoperatório. Ressalta-se que esse teste está contraindicado para pacientes com coronariopatia.

7. Resposta ausente do TSH à administração de TRH (teste do TRH). Sugere fortemente a presença de tireotropinoma. Pacientes normais respondem a este teste com um pico de elevação do TSH (mínimo de $150 \%$ sobre o valor basal) nos tempos iniciais, evoluindo com queda para os valores normais nos tempos mais tardios. Os tumores hipofisários, como comentado previamente, apresentam certa insensibilidade a esse estímulo. Assim, após a administração do fármaco, os pacientes costumam não apresentar incremento sobre o valor basal nem curva fisiológica de elevação do TSH (curva de resposta achatada comparada à fisiológica). Utilizando um incremento maior que $150 \%$ sobre o basal, cerca de $92 \%$ dos tumores hipofisários avaliados apresentavam ausência de resposta nesse teste (3).

8. Resposta do TSH aos análogos da somatostatina (AS) (teste de supressão do TSH com Oct-sc). Este teste visa tanto ao diagnóstico do tumor como à avaliação da resposta do tumor perante um eventual tratamento clínico. Parte da premissa que na SRHT a redução do TSH após a administração desse fármaco é mínima ou ausente $(30,38)$. A existência de redução significativa desse hormônio seria altamente sugestiva da presença de um tumor hipofisário (30). Esse teste levou à redução considerável da secreção em $94 \%$ dos casos avaliados (39).

9. Presença de lesão na RM. Sugere fortemente a presença de tireotropinoma. No entanto, deve-se ressaltar a prevalência de $10 \%$ de incidentalomas hipofisários nas imagens de RM na população normal (40). Observa-se que $90 \%$ dos tumores secretores de TSH são macroadenomas, podendo haver $10 \%$ de microadenomas. Entre os macroadenomas, observa-se que $71 \%$ possuem extensão extrasselar e, dentre esses, $35 \%$ são francamente invasivos. Quando analisados os casos com terapia ablativa tireoidiana prévia, constatou-se que o número com extensão extrasselar chega a ser maior que $80 \%$ em comparação aos pacientes não tratados. Esse dado, em conjunto com os níveis hormonais, sugere que os tumores são parcialmente sensíveis à queda das concentrações dos hormônios tireoidianos e que a terapia ablativa prévia pode levar a um fenômeno "Nelson-like". Não se documentou relação entre o tamanho tumoral e a secreção de TSH (3). Outro método de imagem também utilizado é o mapeamento com Octreoscan, que usa, mais frequentemente, o pentreotide marcado com Indium ${ }^{111}$ como traçador. A experiência clínica tem demonstrado que esse é um método de baixa sensibilidade (19), provavelmente pela maior afinidade do fármaco ao SSTR3 do que ao SSTR2 (41). Além disso, sua especificidade é baixa, pois pode se ligar a outros tumores hipofisários, funcionantes ou não. Esse teste também não demonstrou correlação entre sua positividade e a resposta ao tratamento clínico com Oct (42). Poderia, no entanto, ser de importância para localizar tireotropinomas ectópicos (4).

Além da SRHT, outras condições que também devem ser consideradas no diagnóstico diferencial do tireotropinoma são:

1. Condições clínicas nas quais as determinações de hormônios tireoidianos e do TSH são realizadas fora de condições de equilíbrio do eixo hipófise-tireoide. Exemplos: pacientes na fase inicial de tireoidite subaguda, pacientes com hipotireoidismo em tratamento irregular ou de curta duração com levotiroxina etc.

2. Pacientes com elevação dos níveis de T4 e T3 totais por aumento nas proteínas transportadoras associado a níveis de TSH normais. Nesses casos, o T4 livre está normal, compatível com o TSH.

3. Doenças sistêmicas, doenças psiquiátricas, disalbuminemia familiar, situações nas quais as formas totais e livres do T3 e T4 podem sofrer alterações fisiológicas. Outra situação que também deve ser excluída é o uso de medicamentos como amiodarona (em especial pela frequência de uso), heparina em pacientes internados, anfetaminas etc., pois podem levar a alterações laboratoriais.

4. Considerar a presença de fatores que interfiram na dosagem hormonal. Deve-se considerar a presença de anticorpos anti-T4 e anti-T3, que poderiam levar a uma superestimação nos métodos de etapa única, assim como à presença de formas circulantes anômalas de albumina e transtiretina. A presença de anticorpos heterófilos também deve ser considerada, uma vez que ela pode levar à dosagem de níveis elevados de TSH. Por fim, também deve ser considerada a presença de anticorpos anti-TSH, que poderia levar a níveis baixos de TSH e raramente a níveis elevados.

\section{Tratamento}

A primeira opção para o tratamento dos adenomas hipofisários secretores de TSH é a cirurgia. No entanto, essa 
modalidade terapêutica pode não conduzir à cura devido às características dos tumores que frequentemente são macroadenomas, invasivos e de consistência endurecida (19). O tratamento cirúrgico se mostrou eficaz entre $32 \%$ (33) e $84 \%$ (43) dos casos, dependendo do critério de cura considerado. Beck-Peccoz e Persani (31), utilizando como critério de cura a normalização hormonal, observaram eficácia cirúrgica em $68 \%$ dos pacientes. Talvez um critério mais abrangente e mais fidedigno de cura fosse a normalização hormonal, com o desaparecimento do tumor associado à resposta fisiológica ao teste do TRH.

Nos casos de ressecção cirúrgica parcial e não curativa, o tratamento clínico medicamentoso tem sido geralmente utilizado como terapia complementar. A demonstração dos receptores de dopamina e de SSTR nesses adenomas, juntamente com a disponibilidade de agonistas dopaminérgicos e AS, tem permitido essa abordagem terapêutica.

Os AS têm demonstrado eficácia no tratamento (44), obtendo redução do TSH em 90\% dos casos, normalização da função tireoidiana em $75 \%$ e redução significativa do volume tumoral em $50 \%$ do pacientes tratados (45). Tanto o OCT-sc como o Oct-LAR são igualmente eficazes $(45,46)$. Assim, os AS têm sido indicados tanto como terapêutica complementar à cirurgia não curativa quanto como tratamento pré-operatório, visando ao controle do hipertireoidismo (23). Há descrição de mudança no padrão de secreção das isoformas de TSH com a administração dos AS, sugerindo que, além da redução da secreção, também pode haver alteração na bioatividade do TSH sob influência desse fármaco (47). Apesar dos excelentes resultados, situações como escape verdadeiro e resistência ao medicamento podem ocorrer em $10 \%$ e $4 \%$ dos casos, respectivamente (31). Nos tumores resistentes, o insucesso medicamentoso provavelmente deve ser causado pela menor expressão do SSTR2. Esses pacientes poderão se beneficiar, no futuro, de um análogo universal, com maior afinidade a outros SSTR.

Com o objetivo de predizer a resposta dos pacientes ao AS, várias modalidades de testes foram propostas. Losa e cols. (42) propuseram a determinação de TSH 1, 2, 4 e 6 horas após a administração Oct-sc 100 mcg, e consideraram como resposta positiva uma queda de $30 \%$ a $60 \%$ em relação aos valores basais de TSH. Brucker-Davis e cols. propuseram que uma resposta positiva seria uma queda de $88 \%$ nos valores de TSH após Oct-sc $100 \mathrm{mcg} 8 / 8 \mathrm{~h}$ durante três dias (30). Teramoto e cols. (23) realizaram a determinação de TSH antes, 2 , 4,6 e 12 horas após a injeção endovenosa de Oct-sc 50 mcg e consideraram como resposta positiva diminuição de $50 \%$ nas concentrações de TSH. Assim, não existe consenso quanto à dose do Oct-sc a ser administrada, à via, aos tempos de aferição do TSH e qual seria o valor de resposta esperado para o teste.

O Oct também pode ser utilizado como tratamento primário para alguns pacientes, com controle em longo prazo $(14,48)$.

Outra possível opção na terapêutica medicamentosa são os agonistas dopaminérgicos. A resposta do TSH ao uso de agonistas dopaminérgicos, in vivo, varia desde ausência de resposta até resposta paradoxal com elevação da secreção de TSH (27). Vários estudos demonstraram resposta ausente ou mínima na maioria dos casos tratados tanto com cabergolina como com bromocriptina. Apenas alguns tumores mistos secretores de TSH/PRL apresentaram uma resposta positiva $(28,30,31)$.

A radioterapia como tratamento inicial é reservada para pacientes com contraindicação cirúrgica, que recusem cirurgia e que não tenham acesso aos AS. Tem sido geralmente utilizada como tratamento complementar à cirurgia. Beck-Peccoz e Persani (31) observaram que a radioterapia como tratamento primário apresentou eficácia similar à da cirurgia. No entanto, o estudo teve duas limitações: a casuística foi pequena e os critérios de elegibilidade para radioterapia primária não foram suficientemente esclarecidos.

A normalização dos hormônios da tireoide deve ser alcançada no período pré-operatório. Além dos fármacos citados anteriormente, drogas inibidoras da síntese de hormônios tireoidianos, como o metimazol e o propiltiuracil, também podem ser utilizadas com o objetivo de se alcançar o eutireoidismo. Em casos mais resistentes, o uso do ácido iopanoico também pode ser uma opção em associação aos fármacos antitireoidianos (49).

\section{Critérios de cura}

Os critérios para se definir a cura ainda não estão bem definidos na literatura, sendo utilizados critérios diferentes (19) por diversos autores. Considerando que tireotrofos normais estão suprimidos devido à elevação dos hormônios tireoidianos, no pós-cirúrgico imediato o TSH deve permanecer indetectável até que o eixo hipófise-tireoide se recomponha naturalmente. Entretanto, apenas a normalização hormonal não é suficiente para que se possa considerar o paciente como curado ou em remissão da doença. Assim, após a cirurgia, os critérios de cura mais 
aceitos atualmente são: TSH indetectável nos primeiros sete dias após ressecção cirúrgica do tumor, ausência de remanescente tumoral em ressonância magnética três meses após a cirurgia e resposta normal do TSH no teste do TRH (50).

\section{CONCLUSÃO}

Tireotropinomas são tumores raros, de achado pouco frequente na prática clínica, e cerca de um terço dos casos recebe o diagnóstico inadequado de hipertireoidismo primário. Os dois casos apresentados exemplificam as duas modalidades terapêuticas mais eficazes: a cirurgia hipofisária e o uso de AS. A opção para uma ou outra abordagem dependerá de vários fatores, como o grau de comprometimento clínico do paciente, a existência de compressão tumoral significativa e a presença no tumor de receptores somatostatinérgicos que possam ser ativados pelos AS.

Declaração: os autores declaram não haver conflitos de interesse científico neste estudo.

\section{REFERÊNCIAS}

1. Jailer JW, Holub DA. Remission of Graves' disease following radiotherapy of a pituitary neoplasm. Am J Med. 1960;28:497-500.

2. Hamilton C, Adams LC, Maloof F. Hyperthyroidism due to thyrotropin- producing pituitary chromophobe adenoma. N Engl J Med. 1970;283(20):1077-80.

3. Beck-Peccoz P, Brucker-Davis F, Persani L, Smallridge RC, Weintraub BD. Thyrotropin-secreting pituitary tumors. Endocr Rev. 1996;17(6):610-38.

4. Cooper DS, Wenig BM. Hyperthyroidism caused by an ectopic TSH-secreting pituitary tumor. Thyroid. 1996;6(4):337-43.

5. Mixson AJ, FriedmanTC, Katz DA, Feuerstein IM, Taubenberger JK, Colandrea JM, et al. Thyrotropin-secreting pituitary carcinoma. J Clin Endocrinol Metab. 1993;76(2):529-33.

6. Brown RL, MuzzafarT, Wollman R, Weiss RE. A pituitary carcinoma secreting TSH and prolactin: a non-secreting adenoma gone awry. Eur J Endocrinol. 2006;154(5):639-43.

7. Filetti S, Rapoport B, Aron DC, Greenspan FC, Wilson CB, Fraser W. TSH and TSH-subunit production by human thyrotrophic tumour cells in monolayer culture. Acta Endocrinol (Copenh). 1982;99(2):224-31.

8. Beck-Peccoz P, Persani L. Variable biological activity of thyroidstimulating hormone. Eur J Endocrinol. 1994;131(4):331-40.

9. Jaquet $P$, Hassoun J, Delori P, Gunz G, Grisoli F, Weintraub BD. A human pituitary adenoma secreting thyrotropin and prolactin: immuhistochemical, biochemical, and cell culture studies. J Clin Endocrinol Metab. 1984;59(5):817-24.

10. Le Dafniet M, Brandi AM, Kujas M, Chanson P, Peillon F. Thyrotropin-releasing hormone (TRH) binding sites and thyrotropin response to TRH are regulated by thyroid hormones in human thyrotropic adenomas. Eur J Endocrinol. 1994;130(6):559-64.

11. Lamberts SW, Oosterom R, Verleun T, Krenning EP, Assies H. Regulation of hormone release by cultured cells from a thyrotropin-growth hormone-secreting pituitary tumor. Direct inhibiting effects of 3,5,3'-triiodothyronine and dexamethasone on thyrotropin secretion. J Endocrinol Invest. 1984;7(4):313-7.

12. Mantovani S, Beck-Peccoz P, Saccomanno K, Spada A, Faglia G, Barbetti F. TSH-secreting pituitary adenomas are monoclonal in origin. Proceedings of the 77th Annual Meeting of the Endocrine Society. Washington DC. 1995;412(Abstract P2-485).

13. Dong $\mathrm{Q}$, Brucker-Davis F, Weintraub BD, Smallridge RC, Carr FE, Battey J, et al. Screening of candidate oncogenes in human thyrotroph tumors: absence of activating mutations of the Gaq, Ga11, Gas, or thyrotropin-releasing hormone receptor genes. J Clin Endocrinol Metab. 1996;81(3):1134-40.

14. Pellegrini I, Barlier A, Gunz G, Figarella-Branger D, Enjalbert A, Grisoli $F$, et al. Pit-I gene expression in the human pituitary and pituitary adenomas. J Clin Endocrinol Metab. 1994;79:189-96.

15. Lania A, Mantovani G, Spada A. Genetics of pituitary tumors: focus on G-proteina mutations. Exp Biol Med. 2003;228(9):1004-17.

16. Burgess JR, Shepherd JJ, Greenaway TM. Thyrotropinomas in multiple endocrine neoplasia type 1 (MEN-I). Aust N Z J Med. 1994;24(6):740-1.

17. Lamberg BA, Ripatti J, Gordin A, Juustila H, Sivula A, Björkesten G. Chromophobe pituitary adenoma with acromegaly and TSHinduced hyperthyroidism associated with parathyroid adenoma. Acta Endocrinol (Copenh). 1969;60(1):157-72.

18. Wynne AG, Gharib H, Scheithauer BW, Davis DH, Freeman SL, Horvarth E. Hyperthyroidism due to inappropriate secretion of thyrotropin in 10 patients. Am J Med. 1992;92(1):15-24.

19. Socin HV, Chanson P, Delemer B, Tabarin A, Rohmer V, Mockel J, et al. The changing spectrum of TSH-secreting pituitary adenomas: diagnosis and management of 43 patients. Eur J Endocrinol. 2003;148(4):433-42.

20. Boggild MD, Jenkinson S, Pistorello M, Boscaro M, Scanarini M, McTeman $P$, et al. Molecular genetics studies of sporadic pituitary tumors. J Clin Endocrinol Metab. 1994;78(2):387-92.

21. Ando S, Sarlis NJ, Oldfield EH, Yen PM. Somatic mutation ofTRbeta can cause a defect in negative regulation of TSH in aTSH-secreting pituitary tumor. J Clin Endocrinol Metab. 2001;86(11):5572-76.

22. Ezzat S, Horvath E, Kovacs K, Smyth HS, Sriger W, Asa SL. Basic fibroblast growth factor expression by two prolactina and thyrotropinproducing pituitary adenomas. Endocr Pathol. 1995;6(2):125-34.

23. Teramoto A, Sanno N, Tahara S, Osamura YR. Pathological study of thyrotropin- secreting pituitary adenoma: plurihormonality and medical treatment. Acta Neuropathol. 2004;108(2):147-53.

24. Asa SL, Horvath E, Kovacs KT. Functional pituitary anatomy and histology. In: Melmed S. Endocrinology. 4. ed. Philadelphia: W.B. Sauders Company; 2001. p. 168-82.

25. Horiguchi K, Yamada M, Umezawa R, Satoh T, Hashimoto K, Tosaka $M$, et al. Somatostatin receptor subtypes mRNA in TSH-secreting pituitary adenomas: a case showing a dramatic reduction in tumor size during short octreotide treatment. Endocr J. 2007;54(3):371-8.

26. Yoshihara A, Isozaki O, Hizuka N, Nozoe Y, Harada C, Ono M, et al. Expression of type 5 somatostatin receptor in TSH-secreting pituitary adenomas: a possible marker for predicting long-term response to octreotide therapy. Endocr J. 2007;54(1):133-8.

27. Chanson P, Orgiazzi J, Derome PJ, Bression D, Jedynak CP, Trouillas $\mathrm{J}$, et al. Paradoxical response of thyrotropin to L-dopa and presence of dopaminergic receptors in a thyrotropin-secreting pituitary adenoma. J Clin Endocrinol Metab. 1984;59(3):542-6.

28. Bevan JS, Burke CW, Esiri MM, Adams CB, Ballabio M, Nissim M, et al. Studies of two thyrotrophin-secreting pituitary adenomas: evidence for dopamine receptor deficiency. Clin Endocrinol (Oxf). 1989;31(1):59-70.

29. Mindernann T, Wilson CB. Thyrotropin-producing pituitary adenomas. J Neurosurg. 1993;79(4):521-7.

30. Brucker-Davis F, Oldfield EH, Skarulis MC, Doppman JL, Weintraub BD. Thyrotropin-secreting pituitary tumors: diagnostic criteria, thyroid hormone sensitivity and treatment outcome in 25 patients 
followed at the National Institutes of Health. J Clin Endocrinol Metab. 1999;84(2):476-86.

31. Beck-Peccoz P, Persani L. Medical management of thyrotropinsecreting pituitary adenomas. Pituitary. 2002;5(2):83-8.

32. Beck-Peccoz P, Roncoroni R, Mariotti S, Medri G, Marcocci C, Brabant G. Sex hormone-binding globulin measurement in patients with inappropriate secretion of thyrotropin (IST): evidence against selective pituitary thyroid hormone resistance in nonneoplastic IST. J Clin Endocrinol Metab. 1990;71(1):19-25.

33. Persani L, Preziati $\mathrm{D}$, Matthews $\mathrm{CH}$, Sartorio A, Chatterjee VK, Beck-Peccoz P. Serum levels of carboxyterminal cross-linked telopeptide of type I collagen (ICTP) in the differential diagnosis of the syndromes of inappropriate secretion ofTSH. Clin Endocrinol (Oxf). 1997;47(2):207-14.

34. Beck-Peccoz P, Persani L, Faglia G. Glycoprotein hormone $\alpha$-subunit in pituitary adenomas. Trends Endocrinol Metab. 1992;3(2):41-5.

35. Melmed S, Kleinberg D. Anterior pituitary. In: Larsen PR, Kronenberg HM, Melmed S, Polonsky KS, editors. Willians Textbook of Endocrinology. 10. ed. Philadelphia: Sauders; 2003. p. 250-1.

36. Vilar L. Naves LA. Adenomas secretores de TSH - Abordagem diagnóstico-terapêutica. In: Vilar L, et al. Ed. Endocrinologia clínica. 2. ed. Rio de Janeiro: Medsi; 2001. p. 81-6.

37. Saad B, Liu A, Brucker-Davis F, Spencer C, LoPresti J, Nicoloff J. Simplified screening test for resistance to thyroid hormone (RTH) - The T3 challenge test (T3CT). Proceedings of the 77th meeting of The Endocrine Society. Washington DC. 1995:211 (Abstract I'-396).

38. Beck-Peccoz P, Mariotti S, Guillausseau PJ, Medri G, Piscitelli G, Bertoli $A$, et al. Treatment of hyperthyroidism due to inappropriate secretion of thyrotropin with the somatostatin analog SMS 201-995. J Clin Endocrinol Metab. 1989;68(1):208-14.

39. Chanson P, Weintraub BD, Harris AG. Octreotide therapy for thyroid stimulating-secreting pituitary adenomas. A follow-up of 52 patients. Ann Intern Med. 1993;119(3):236-40.

40. Hall WA, Luciano MG, Doppman JL, Patronas NJ, Oldfield EH. Pituitary magnetic resonance imaging in normal human volunteers: occult adenomas in the general population. Ann Intern Med. 1994;120(10):817-20.

41. Reubi JC, Schar JC, Waser B, Wenger S, Heppeler A, Schmitt JS, et al. Affinity profiles for human somatostatin receptor subtypes
SST1- SST5 of somatostatin radiotracers selected for scintigraphic and radiotherapeutic use. Eur J Nucl Med. 2000;27(3):27382.

42. Losa M, Magnani P, Mortini P, Persani L, Acerno S, Giugni E, et al. Indium 111 pentetreotide single-photon emission tomography in patients with TSH-secreting pituitary adenomas: correlation with the effect of a single administration of octreotide on serum TSH levels. Eur J Nucl Med. 1997;24(7):728-31.

43. Sanno N, Teramoto A, Osamura RY.Thyrotropin-secreting pituitary adenomas. Clinical and biological heterogeneity and current treatment. J Neurooncol. 2001;54(2):179-86.

44. Bertherat J, Brue T, Enjalbert A, Gunz G, Rasolonjanahary R, Warnet $A$, et al. Somatostatin receptors on thyrotropin-secreting pituitary adenomas: comparison with the inhibitory effects of octreotide upon in vivo and in vitro hormonal secretions. J Clin Endocrinol Metab. 1992;75(2):540-6.

45. Chanson P, Weintraub BD, Harris AG. Octreotide therapy for thyroid-stimulating hormone-secreting pituitary adenomas. A follow-up of 52 patients. Ann Intern Med. 1993;119(3):236-40.

46. Caron P, Arlot S, Bauters C, Chanson P, Kuhn JM, Pugeat M, et al. Efficacy of the long-acting octreotide formulation (octreotideLAR) in patients with thyrotropin-secreting pituitary adenomas. J Clin Endocrinol Metab. 2001;86(6):2849-53.

47. Francis TB, Smallridge RC, Kane J, Magner JA. Octreotide changes serum thyrotropin (TSH) glycoisomer distribution as assessed by lectin chromatography in a TSH macroadenoma patient. J Clin Endocrinol Metab. 1993;77(1):183-7.

48. Ness-Abramof R, Ishay A, Harel G, Sylvetzky N, Baron E, Greenman $\mathrm{Y}$, et al. TSH-secreting pituitary adenomas: follow-up of 11 cases and review of the literature. Pituitary. 2007;10(3):307-10.

49. Dhillon KS, Cohan P, Kelly DF, Darwin CH, Iyer KV, Chopra IJ. Treatment of hyperthyroidism associated with thyrotropin-secreting pituitary adenomas with iopanoic acid. J Clin Endocrinol Metab. 2004;89(2):708-11.

50. Losa M, Giovanelli M, Persani L, Mortini P, Faglia G, Beck-Peccoz P. Criteria of cure and follow-up of central hyperthyroidism due to thyrotropin-secreting pituitary adenomas. J Clin Endocrinol Metab. 1996;81(8):3084-90. 